\title{
Corrigendum: Leishmanicidal activities of Artemisia annua leaf essential oil against Visceral Leishmaniasis
}

\begin{abstract}
Mohammad Islamuddin ${ }^{1}$, Garima Chouhan ${ }^{1}$, Muzamil Y. Want ${ }^{1}$, Maujiram Tyagi ${ }^{2}$, Malik Z. Abdin ${ }^{2}$, Dinkar Sahal ${ }^{3}$ and Farhat Afrin ${ }^{4 *}$

1 Parasite Immunology Lab, Department of Biotechnology, Jamia Hamdard (Hamdard University), New Delhi, India, ${ }^{2}$ Department of Biotechnology, Centre for Transgenic Plant Development, Jamia Hamdard (Hamdard University), New Delhi, India, ${ }^{3}$ Malaria Group, International Centre for Genetic Engineering and Biotechnology, New Delhi, India, ${ }^{4}$ Department of Medical Laboratories Technology, Faculty of Applied Medical Sciences, Taibah University, Medina, Saudi Arabia
\end{abstract}

Keywords: leishmaniasis, visceral, essential oil, Artemisia annua, leishmanicidal, apoptosis, therapeutic efficacy

\section{A corrigendum on}

Leishmanicidal activities of Artemisia annua leaf essential oil against Visceral Leishmaniasis by Islamuddin, M., Chouhan, G., Tyagi, M., Abdin, M. Z., Sahal, D., and Afrin, F. (2014). Front. Microbiol. 5:626. doi: 10.3389/fmicb.2014.00626

OPEN ACCESS

Edited and reviewed by: Luis Cláudio Nascimento Da Silva, University of Copenhague, Denmark

*Correspondence: Farhat Afrin afrin_farhat@yahoo.co.in farhatafrin@gmail.com

Specialty section This article was submitted to Antimicrobials, Resistance and Chemotherapy,

a section of the journal

Frontiers in Microbiology

Received: 30 August 2015 Accepted: 07 September 2015 Published: 24 September 2015

Citation: Islamuddin M, Chouhan G, Want MY

Tyagi M, Abdin MZ, Sahal D and

Afrin $F$ (2015) Corrigendum: Leishmanicidal activities of Artemisia annua leaf essential oil against Visceral

Leishmaniasis.

Front. Microbiol. 6:1015. doi: 10.3389/fmicb.2015.01015
The author Muzamil Y. Want was inadvertently missed in the original manuscript and we wish to add his name for contribution to ex vivo experiments.

\section{Author Contributions}

MI, FA conceived and designed the experiments. MI, FA, GC performed the experiments. MW assisted in ex vivo experiments while MT, DS, and MA assisted in extraction of oil. FA, MI analyzed the data and wrote the manuscript.

The affiliation/correspondence address of the Corresponding author had a minor error, which we hereby rectify. It was incorrectly written as:

Department of Medical Laboratories Technology, Faculty of Applied Sciences, Taibah University, PO Box 344, Universities Road, Medina 30001, Saudi Arabia

The correct version is:

Department of Medical Laboratories Technology, Faculty of Applied Medical Sciences, Taibah University, PO Box 344, Universities Road, Medina 30001, Saudi Arabia

Conflict of Interest Statement: The authors declare that the research was conducted in the absence of any commercial or financial relationships that could be construed as a potential conflict of interest.

Copyright (c) 2015 Islamuddin, Chouhan, Want, Tyagi, Abdin, Sahal and Afrin. This is an open-access article distributed under the terms of the Creative Commons Attribution License (CC BY). The use, distribution or reproduction in other forums is permitted, provided the original author(s) or licensor are credited and that the original publication in this journal is cited, in accordance with accepted academic practice. No use, distribution or reproduction is permitted which does not comply with these terms. 